\title{
Air-sea momentum flux climatologies: A review of drag relation for parameterization choice on wind stress in the North Atlantic and the European Arctic
}

Iwona Wrobel-Niedzwiecka, Violetta Drozdowska, Jacek Piskozub ${ }^{1}$

${ }^{1}$ Institute of Oceanology, Polish Academy of Science, ul. Powstancow Warszawy 55, 81-712 Sopot, Poland corresponding author: iwrobel@iopan.gda.pl

Key points: drag coefficient, European Arctic, North Atlantic, parameterizations

\section{Abstract}

In this paper we have chosen to check the differences between the relevant or most commonly used parameterizations for drag coefficient $\left(C_{D}\right)$ for the momentum transfer values, especially in the North Atlantic (NA) and the European Arctic (EA). As is well know, the exact equation in the North equation that describes the connection betwenn the drag coefficient and wind speed depends on the author. We studied monthly values of air-sea momentum flux resulting from the choice of different drag coefficient parameterizations, adapted them to momentum flux (wind stress) calculations using SAR wind fields, sea-ice masks, as well as integrating procedures. We calculated monthly momentum flux averages on a $1^{\circ} \mathrm{x} 1^{\mathrm{o}}$ degree grid and derive average values for the North Atlantic and the European Arctic. We compared the resulting spreads in momentum flux to global values and values in the tropics, an area of prevailing low winds. We show that the choice of drag coefficient parameterization can lead to significant differences in resultant momentum flux (or wind stress) values. We found that the spread of results stemming from the choice of drag coefficient parameterization was $14 \%$ in the Arctic, the North Atlantic and globally, but it was higher (19\%) in the tropics. On monthly time scales, the differences were larger at up to $29 \%$ in the North Atlantic and $36 \%$ in the European Arctic (in months of low winds) and even $50 \%$ locally (the area west of Spitsbergen). When we chose the oldest parameterization (e.g Wu, 1969 (W69)) values of momentum flux were largest for all months, in compare to values from the two newest parameterizations (Large and Yeager, 2004 (LY04) and Andreas, 2012 (A12)), in both regions with high and low winds and $C_{D}$ values were consistently higher for all wind speeds. For global data not much seasonal change was note due to the fact that the strongest winds are in autumn and winter as these seasons are inverse by six months for the northern and southern hemispheres. The situation was more complicated when we considered results from the North Atlantic, as the seasonal variation in wind speed is clearly marked out there. With high winter winds, the A12 parameterization was no longer the one that produces the smallest wind stress. In this region, in summer, the highest wind stress values were produced by the NCEP/NCAR reanalysis, where in $C_{D}$ has a constant value. However, for low summer winds, it is the lowermost outlier. As the A12 parameterization behaves so distinctly differently with low winds, we showed seasonal results for the tropical ocean. The sequence of values for the parameterization was similar to that of the global ocean, but with visible differences betwenn NCEP/NCAR, A12 and LY04 parameterizaions. Because parameterization is supported with the largest experimental data set observations of very low (or even negative) momentum flux 
values for developed swell and low winds, our results suggest that most circulation models overestimate momentum flux.

\section{Introduction}

Wind stress acts at the air-sea interface influence on wind-wave interaction, including wind-driven surface waves, turbulence in upper and deep layers, drift currents, and the main ocean currents (Zilitinkiewicz et al., 1978). The ocean surface mixed layer is a region where kinematic forcing affects the exchange of horizontal momentum and controls transport from the surface to depths (Gerbi et al., 2008, Bigdeli et al., 2017). Any attempt to properly model the momentum flux from one fluid to another as the drag force per unit area at the sea surface (surface shear stress, $\tau$ ) must take into account other physical processes responsible for generating turbulence such as boundary stress, boundary buoyancy flux, and wave breaking (Rieder et al., 1994, Jones and Toba, 2001). Over the past fifty years, as the entirety of flux data has increased many fold, multiple empirical formulas have been developed to express the ocean surface momentum flux as a relationship between non-dimensional drag coefficient $\left(C_{D}\right)$, wind speed $\left(\mathrm{U}_{10}\right)$, and surface roughness $\left(z_{0}\right)(\mathrm{Wu} 1969$, 1982; Bunker, 1976; Garratt, 1977; Large and Pond, 1981; Trenberth et al., 1989; Yelland and Taylor, 1996, Donelan et al., 1997; Kukulka et al., 2007; Andreas et al., 2012). These formulas can be divided into two groups. One group of theories gives the $C_{D}$ at level $z$ in terms of wind speed and possibly one or more sea-state parameters (for example, Geernaert et al., 1987, Yelland and Taylor, 1996, Enriquez and Friehe, 1997), while the second group provides formulas for roughness length $z_{0}$ in terms of atmospheric and sea-state parameters (for example, Wu, 1969, Donelan et al., 1997, Andreas et al., 2012). It is well known that the drag coefficient is not a constant, because surface roughness changes with sea state, and that it is an increasing function of wind speed for moderate wind speeds in the marine atmospheric boundary layer (Foreman and Emeis, 2010). On the other hand, many researchers have recently shown that results for the drag coefficient are underestimated at moderate wind speeds and overestimated at high wind speeds (Jarosz et al., 2007, Sahlée et al., 2012, Peng and Li, 2015, Brodeau et al., 2017).

In this paper we chose to check the differences between the relevant or most commonly used parameterizations for drag coefficient $\left(C_{D}\right)$ for momentum transfer values, especially in the North Atlantic (NA) and the European Arctic (EA). As is widely known, the exact equation that describes the connection between the drag coefficient and wind speed depends on the author (Geernaert, 1990). Our intention here is not to re-invent or formulate a new drag parameterization for the NA or the EA, but to revisit the existing definition of drag parameterization, and, using satellite data, to investigate how existing formulas accommodate the environment in the North. We concentrated on wind speed parameterizations, because wind speed is a parameter that is available in every atmospheric circulation model. Therefore, it is used in all air-sea flux parameterizations, and presently it is used even when sea state provides a closer physical coupling to the drag coefficient (for review see Geernaert et al., 1986). 
To understand air-sea interaction, Taylor (1916) parameterized the wind's drag on the sea surface using the bulk aerodynamic formula:

$$
\tau=\rho C_{D Z} U_{Z}^{2}
$$

where $(\tau)$ is the drag per unit area of sea surface (also called surface stress or momentum flux), $\rho$ is air density, $C_{D z}$ is the non-dimensional drag coefficient appropriate for $z$ height, and $U_{z}$ is the average wind speed at some reference height $z$ above the sea. $C_{D z}$ is commonly parameterized as a function of mean wind speed $\left(\mathrm{m} \mathrm{s}^{-1}\right)$ for neutral-stability at a $10 \mathrm{~m}$ reference height above mean sea level (Jones and Toba, 2001), which is identified as $C_{D N 10}$ or $C_{D 10}$ (this permits avoiding deviation for the vertical flow from the logarithmic law):

$$
C_{D N 10}=\frac{\tau}{\rho} U_{10}^{2}=\left(\frac{u_{*}}{U_{10}}\right)^{2}
$$

where $u_{*}$ is friction velocity. Alternatively, the neutrally stratified momentum flux can be determined from the logarithmic profile, thus Eq. 1 can be express as:

$$
C_{D N 10}=\left[\mathrm{k} / \ln \left(10 / z_{0}\right)\right]^{2}
$$

where $z_{0}(\mathrm{~m})$ is the aerodynamic roughness length, which is the height, above the surface to define the measure of drag at which wind speed extrapolates to 0 on the logarithmic wind profile (Andreas et al., 2012), and $\kappa$ is von Kármán constant $(\kappa=0.4)$.

At the same time, we can define the value of friction velocity $(u *)$ as having the dimension of velocity, which is defined by the following equation:

$$
\tau=\rho u_{*}^{2}
$$

Comparison with bulk formula (1) leads to the equation:

$$
u_{*}^{2}=C_{D 10} U_{10}^{2}
$$

Some of the first studies (Wu, 1969, 1982, Garrat, 1977) focused on the relationship between wind stress and sea surface roughness, as proposed by Charnock (1955), and they formulated (for winds below $15 \mathrm{~m} \mathrm{~s}^{-1}$ ) the logarithmic dependence of the stress coefficient on wind velocity (measured at a certain height) and the von Kármán constant. Currently common parameterizations of the drag coefficient are a linear function of $10 \mathrm{~m}$ wind speed $\left(\mathrm{U}_{10}\right)$, and the parameters in the equation are determined empirically by fitting observational data to a curve. The general form is expressed as (Guan and Xie, 2004):

$$
C_{D} 10^{3}=\left(a+b U_{10}\right)
$$

$\mathrm{Wu}$ (1969), based on data compiled from 12 laboratory studies and 30 oceanic observations, formulated power-law (for breezes and light winds) and linear-law (for strong winds) relationships between the wind-stress coefficient $\left(C_{y}\right)$ and wind velocity $\left(\mathrm{U}_{10}\right)$ at a certain height $y$ at various sea states. In his study, he used roughness Reynolds numbers to 
characterize the boundary layer flow conditions, and he assumed that the sea surface is aerodynamically smooth in the range of $\mathrm{U}_{10}<3 \mathrm{~m} \mathrm{~s}^{-1}$, transient at wind speed $3 \mathrm{~m} \mathrm{~s}^{-1}<\mathrm{U}_{10}<$ $7 \mathrm{~m} \mathrm{~s}^{-1}$, and aerodynamically rough at strong winds $U_{10}>7 \mathrm{~m} \mathrm{~s}^{-1}$. He also showed that the wind-stress coefficient and surface roughness increase with wind speed at light winds $\left(\mathrm{U}_{10}<\right.$ $\left.15 \mathrm{~m} \mathrm{~s}^{-1}\right)$ and is constant at high winds $\left(\mathrm{U}_{10}>15 \mathrm{~m} \mathrm{~s}^{-1}\right)$ with aerodynamically rough flow. Garratt (1977), who assessed the $10 \mathrm{~m}$ neutral drag coefficient $\left(C_{D N 10}\right)$ based on 17 publications, confirmed the previous relationship and simultaneously suggested a linear form of this relationship for light wind. Wu (1980) proposed the linear-law formula for all wind velocities and later (Wu, 1982) extended this even to hurricane wind speeds. All of the preceding results rely heavily on the Monin-Obukhov similarity theory (MOST) in order to eliminate the stability dependence by choosing $10 \mathrm{~m}$ as the standard reference height and using data obtained under different experimental conditions (laboratory or field) and data analysis. In 1981, Large and Pond's estimated momentum flux using the direct Reynolds flux method and the dissipation method indicated the linear-law of $C_{D}$ for wind speed in moderate winds. Their results confirm the assumption that the neutral drag coefficient increases with higher wind speed values and support the theoretical prediction that $C_{D N}$ is independent of the bulk stability parameter (z/L). Trenberth et al. (1989), who considered the uncertainty in $C_{D}$ from earlier experiments in which there were difficulties in calculations for low frequency (less than 10 days), suggest incorporating a quantity called pseudostress (P), which assumes using an effective drag coefficient and constant air density. Their results were based on data from the European Centre for Medium Range Weather Forecasts (ECMWF) collected over seven years. Yelland and Taylor (1996) presented results obtained from three cruises using the inertial dissipation method in the Southern Ocean and indicate that using the linear-law relationship between the drag coefficient and wind speed (for $\mathrm{U}_{10}>6 \mathrm{~m} \mathrm{~s}^{-1}$ ) is better than using friction velocities $(u *)$ with $U_{10}$. Fairall et al. (2003) used the COARE algorithm (Coupled Ocean-Atmosphere Response Experiment) globally as a function of ambient conditions. Their results with direct covariance flux measurements showed increases in $\mathrm{C}_{\mathrm{DN} 10}$ values from $1.0 \times 10^{-3}$ to $2.3 \times 10^{-3}$ (or to $2.07 \times 10^{-3}$ if inertial dissipation fluxes were used) with increasing wind speed (from $3 \mathrm{~m} \mathrm{~s}^{-1}$ to $20 \mathrm{~m} \mathrm{~s}^{-1}$ ). All of these studies show that coefficients are not identical and vary with wind speed and atmospheric stability.

Authors of coupled circulation models preferred even simpler parameterizations. The NCEP/ NCAR reanalysis (Kalnay et al., 1996) uses a constant drag coefficient of $1.3 \times 10^{-3}$ while, for example, the Community Climate System Model version 3 (Collins et al., 2006) uses a single mathematical formula proposed by Large and Yeager (2004) for all wind speeds. Their parameterizations explicitly or implicitly assume that equation (6) is exact. However, Foreman and Emeis (2010) show that friction velocity is proportional to wind speed, but with offset:

$$
u_{*}=a U_{10}^{2}+b
$$

Andreas et al. (2012), further referred to as A12, updated equation (8) based on available datasets, friction velocity coefficient $(u *)$ versus neutral-stability wind speed at $10 \mathrm{~m}\left(\mathrm{U}_{\mathrm{N} 10}\right)$, and sea surface roughness $\left(z_{0}\right)$, to find the best fit for parameters $a=0.0583$ and $b=-0.243$. 
They justify their choice by demonstrating that $\mathrm{u}_{*} \mathrm{vs} . \mathrm{U}_{\mathrm{N} 10}$ has smaller experimental uncertainty than $C_{D N 10}$, and that one expression of $C_{D N 10}$ for all wind speeds overstates and overestimates results in low and high winds (Figs. 7 and 8 in A12).

This led directly to a new $C_{D}$ formulation with much lower values for light winds (4 $9 \mathrm{~m} \mathrm{~s}^{-1}$ ). These low values could explain why the observed momentum flux with light winds and fast traveling swell can even be negative (Grachev and Fairall, 2001; Hanley and Belcher, 2008), and if true, this means that all previous parameterizations overestimate wind stress in basins with prevailing light winds (for example, the tropics).

All the above studies propose different parameterizations (see Fig. 1) of the drag coefficient and the function of wind speed, which reflects the difficulties in simultaneously measuring at hight sea stress (or friction velocity) and wind speed. The purpose of this study is to show how the choice of $C_{D}$ parameterization influences the value of the momentum flux from the atmosphere to the ocean with observations based on wind fields in different parts of the ocean, but especially in the NA and the EA seas.

\section{Materials and Methods}

We calculated monthly and annual mean momentum fluxes using a set of software processing tools called FluxEngine (Shutler et al., 2016), which was created as part of the OceanFlux Greenhouse Gases project funded by the European Space Agency (ESA). Since the toolbox, for now, is designed to calculate only air-sea gas fluxes but it does contain the necessary datasets for other fluxes, we made minor changes in the source code by adding parameterizations for the air-sea drag relationship. For the calculations, we used Earth Observation (EO) wind speed data at $10 \mathrm{~m}$ above sea level for 1992-2010 and sea roughness $(\sigma 0$ - altimeter backscatter signal in the $\mathrm{Ku}$ band) from the GlobWave project (http://globwave.ifremer.fr/). GlobWave produced a 20-year time series of global coverage multi-sensor cross-calibrated wave and wind data, which are publicly available at the Ifremer/CERSAT cloud. Satellite scatterometer derived wind fields are at present believed to be at least equally as good as wind products from reanalyses (see, for example, Dukhovskoy et al. 2017) for the area of our interest in the present study. The scatterometer derived wind values are calibrated to the equivalent neutral-stability wind at a reference height of $10 \mathrm{~m}$ above the sea surface, and, therefore, are fit for use with the neutral-stability drag coefficient (Chelton and Freilich, 2005). Wave data were collected from six altimeter missions (like Topex/POSEIDON, Jason-1/22, CryoSAT, etc.) and from ESA Synthetic Aperture Radar (SAR) missions (ERS-1/2 and ENVISAT). All data came in netCDF-4 format. The output data is a compilation file that contains data layers, and process indicator layers. The data layers within each output file include statistics of the input datasets (e.g., variance of wind speed, percentage of ice cover), while the process indicator layers include fixed masks as land, open ocean, coastal classification, and ice.

All analyses using the global data contained in the FluxEngine software produced a gridded $\left(1^{\circ} \times 1^{\circ}\right)$ product. The NA was defined as all sea areas in the Atlantic sector north of $30^{\circ} \mathrm{N}$, and the EA subset was those sea areas north of $64^{\circ} \mathrm{N}$ (Fig. 6). We also defined the 
subset of the EA east of Svalbard ("West Svalbard" between $76^{\circ}$ and $80^{\circ} \mathrm{N}$ and $10^{\circ}$ to $16^{\circ} \mathrm{E}$ ), because it is a region that is studied intensively by multiple, annual oceanographic ship deployments (including that of the R/V Oceania, the ship of the institution the authors are affiliated with). FluxEngine treats areas with sea-ice presence in a way that is compatible with Lüpkes et al. (2012) multiplying the water drag coefficient by the ice-free fraction of each grid element. We also define "tropical ocean" as all areas within the Tropics $\left(23^{\circ} \mathrm{S}\right.$ to $23^{\circ} \mathrm{N}$, not show) in order to test the hypothesis that the new A12 parameterization will produce significantly lower wind stress values in the region.

In this study, we calculated air-sea momentum flux average values using seven different drag coefficient parameterizations $\left(C_{D}\right)$. All of them are generated from the vertical wind profile, but they differ in the formulas used.

$$
10^{3} \cdot C_{D 10}=0.5 U_{10}^{0.5} \quad \text { for } 1 \mathrm{~m} \mathrm{~s}^{-1}<U_{10}<15 \mathrm{~m} \mathrm{~s}^{-1}
$$

(Wu, 1969)

$$
10^{3} \cdot C_{D N 10}=0.75+0.067 U_{10} \quad \text { for } 4 \mathrm{~m} \mathrm{~s}^{-1}<U<21 \mathrm{~m} \mathrm{~s}^{-1}
$$

(Garratt, 1977)

$$
10^{3} \cdot C_{D 10}=\left(0.8+0.065 U_{10}\right) \quad \text { for } U_{10}>1 \mathrm{~m} \mathrm{~s}^{-1}
$$

(Wu, 1982)

$$
\begin{aligned}
& 10^{3} \cdot C_{D N 10}=0.29+\frac{3.1}{U_{10 N}}+\frac{7.7}{U_{10 N}^{2}} \quad \text { for } 3 \mathrm{~m} \mathrm{~s}^{-1}<U_{10 \mathrm{~N}}<6 \mathrm{~m} \mathrm{~s}^{-1} \\
& 10^{3} \cdot C_{D N 10}=0.60+0.070 U_{10 N} \quad \text { for } 6 \mathrm{~m} \mathrm{~s}^{-1}<U_{10 \mathrm{~N}}<26 \mathrm{~m} \mathrm{~s}^{-1} \\
& 10^{3} \cdot C_{D N 10}=\frac{2.7}{U_{10 N}}+0.142+0.076 U_{10 N} \quad \text { everywhere } \\
& \text { (Large and Yeager, 2004) } \\
& C_{D N 10}=\frac{u *}{U_{10 N}}=a^{2}\left(1+\frac{b}{a} U_{10 N}^{2}\right) \\
& \text { where } \quad a=0.0583, b=-0.243 \\
& \text { everywhere }
\end{aligned}
$$

where $C_{D N 10}$ is the expression of neutral-stability (10-m drag coefficient), $C_{D I 0}$ is the drag coefficient dependent on surface roughness, $U_{10}$ is the mean wind speed measured at $10 \mathrm{~m}$ above the mean sea surface, $\mathrm{U}_{10 \mathrm{~N}}$ is the $10-\mathrm{m}$, neutral-stability wind speed.

\section{Results and Discussion}

Using FluxEngine software, we produced monthly gridded global air-sea momentum fluxes data. We calculated average momentum flux values separately for each month for the global ocean, the NA Ocean, and its subsets: the Arctic sector of the NA and the West 
Spitsbergen area (WS). Some of the parameterizations used were limited to a restricted wind speed domain. We used them for all the global wind speed data to avoid data gaps for winds that were too high or too low for a given parameterization (Fig. 1). However, circulation models have the very same constraint and, therefore, the procedure we used emulated using the parameterization in oceanographic and climate modeling.

Since wind velocity was used to estimate $C_{D}$, Fig. 1 shows a wide range of empirical formulas and Fig. 6 shows annual mean wind speed $U_{10}\left(\mathrm{~m} \mathrm{~s}^{-1}\right)$ in the NA and the EA. The differences between the oldest (eq. 8 - 10) and the newer (eq. 11, 13, 14) parameterizations are distinct (Fig. 1). The $C_{D}$ values from the oldest parameterizations increased linearly with wind speed since the results from newer ones are sinusoidal indicating decreases for winds in the range of $0-10 \mathrm{~m} \mathrm{~s}^{-1}$, after which they began increase. Under weak winds $\left(<10 \mathrm{~m} \mathrm{~s}^{-1}\right)$, the drag coefficient values were significantly lower than under stronger winds $\left(>10 \mathrm{~m} \mathrm{~s}^{-1}\right)$, with greater differences among all used parameterizations. At a wind value of about $15 \mathrm{~m} \mathrm{~s}^{-1}$, the results from eq. 9, 10, and 14 overlapped providing the same values for the drag coefficient parameterizations. The annual mean wind speed in the NA is $10 \mathrm{~m} \mathrm{~s}^{-1}$, and in the EA it is 8.5 $\mathrm{m} \mathrm{s}^{-1}$ (Fig. 6).

Figure 2 presents maps of the mean boreal winter DJF and summer JJA momentum fluxes for the chosen $C_{D}$ parameterizations (Wu, 1969 and $\mathrm{A} 12$ - the ones with the largest and smallest $C_{D}$ values). The supplementary materials contain complete maps of annual and seasonal means for all the parameterizations. The zones of the strongest winds are in the extra-tropics in the winter hemisphere (southern for JJA and northern for DJF). The older Wu (1969) parameterization produces higher wind stress values than A12 in both regions with high and low winds and $C_{D}$ values are consistently higher for all wind speeds except the lowest ones (which, after multiplying by $\mathrm{U}^{2}$, produced negligible differences in wind stress for the lowest winds). The average monthly values for each of the studied areas are shown in Fig. 3. Generally, this illustrates that the newer the drag coefficient parameterization is, the smaller the calculated momentum flux is. For global data (Fig. 3a), not much seasonal change is noted, because the strongest winds are in fall and winter, but these seasons are the opposite in the northern and southern hemispheres. The parameterization with the largest momentum flux values for all months is that of $\mathrm{Wu}$ (1969), the oldest one, while the two parameterizations with the lowest values are the newest ones (Large and Yeager, 2004 and A12). For the NA (Fig. 3b), with is much more pronounced seasonal wind changes, the situation is more complicated. With high winter winds, the A12 parameterization is no longer the one that produces the smallest wind stress (it is actually in the middle of the seven). However, for low summer winds, it is the lowermost outlier. Actually, in summer, the constant $C_{D}$ value used by the NCEP/NCAR reanalysis produces the highest wind stress values in the Na. The situation is similar for the EA (a subset of the NA), the wind stress values of which are shown in Fig. 3c, and for the WS area (not show). In the Arctic summer, A12 produces the least wind stresses, while all the other parameterizations look very similar qualitatively (even more so in the Arctic than in the whole NA). Because the A12 parameterization behaves so distinctly differently with low winds, we also show seasonal results for the tropical ocean (Fig. 3d). The seasonal changes are subdued for the whole 
tropical ocean with the slight domination of the Southern Hemisphere (the strongest winds are during the boreal summer) with generally lower momentum transfer values (monthly averages in the range of 0.2 to $0.3 \mathrm{~N} \mathrm{~m}^{-2}$ compared to 0.2 to $0.4 \mathrm{~N} \mathrm{~m}^{-2}$ for the NA and 0.2 to $0.5 \mathrm{~N} \mathrm{~m}^{-2}$ for the Arctic). The sequence of values for the parameterization is similar to that of the global ocean, but there are differences. Here the NCEP/NCAR constant parameterization is the second highest (instead of Wu, 1982 for the global ocean) while, unlike in the case of the global ocean, A12 produces visibly lower values than does the Large and Yeager (2004) parameterization.

We compared directly the results of the two parameterizations for the drag air-sea relation that uses different dependencies (Fig. 4). For this estimation we chose the two mostrecent parameterizations (eq. 13 and 14) that showed the lowest values and change seasonally depending on the area used. This comparison showed that the A12 parameterization demonstrates almost zero sea surface drag for winds in the range of $3-5 \mathrm{~m} \mathrm{~s}^{-1}$, which is compensated for by a certain surplus value for strong winds. As a result, these months with weak winds have significantly lower momentum flux values. This could be at statistical effect of weak wind ocean areas having stable winds with waves traveling in the same direction as the wind at similar speeds. The small drag coefficient values facilitate what Grachev and Fairall (2001) describe as the transfer of momentum from the ocean to the atmosphere at wind speeds of 2 - $4 \mathrm{~m} \mathrm{~s}^{-1}$, which correspond to the negative drag coefficient value. Such events require specific meteorologist conditions, but this strongly suggests that the average $C_{D}$ value for similar wind speeds could be close to zero.

Table 1 and Fig. 5 present the average air-sea momentum flux values (in $\mathrm{N} \mathrm{m}^{-2}$ ) for all the regions studied and all the parameterizations. All the values are also presented as percentages of A12, which produced the lowest values for each region. A surprising result is the proportionality of all the parameterizations for the global, the NA, and the Arctic regions on annual scales (Fig. 3 shows that this is not true on monthly scales). The spread of the momentum flux results is $14 \%$ in all three regions, and even flux values themselves are larger in the NA than globally and larger in the Arctic than in the whole of the NA basin. The smaller WS region, with winds that are, on average, weaker than those of the whole Arctic (but stronger than those of the whole NA), had slightly different ratios of the resultant fluxes. For the tropical ocean, which is included for comparison because of its weaker winds, the spread in momentum flux values on an annual scale is $19 \%$. The spreads are even larger on monthly scales (not shown). The difference between A12 and Wu (1969) and NCEP/NCAR (the two parameterizations producing the largest fluxes on monthly scales) are $27 \%$ and $29 \%$ for the NA (in July), $31 \%$ and $36 \%$ for the Arctic (in June), $42 \%$ and $51 \%$ for the WS region (in July) and $23 \%$ and $22 \%$ for the tropical ocean (in April), respectively. Seasonality in the tropics is weak, therefore, the smallest monthly difference of $16 \%$ (July) is larger than the difference for the global data in any month (the global differences between the parameterizations have practically no seasonality). On the other hand, the smallest monthly differences between the parameterizations in the NA, the Arctic, and the WS regions are all $7 \%$, in the month of the strongest winds (January). 
Because the value of momentum flux is important for ocean circulation, its correct calculation in coupled models is very important, especially in the Arctic, where cold halocline stratification depends on the amount of mixing (Fer, 2009). We show that with the parameterization used in modelling, such as the NCEP/NCAR constant parameterization and Large and Yeager (2004), production stress results differ by about $5 \%$, on average (both in the Arctic and globally), and the whole range of parameterizations leads to results that differ, on average, by $14 \%$ (more in low wind areas) and much more on monthly scales. One aspect that needs more research is the fact that the newest parameterization, A12, produces less momentum flux than all the previous ones, especially in lower winds (which, by the way, continues the trend of decreasing values throughout the history of the formulas discussed). The A12 parameterization is based on the largest set of measurements of friction velocity as a function of wind speed and utilizes the recently discovered fact that $b$ in equation (8) is not negligible. It also fits the observations that developed swell at low wind velocity has celerity which leads to zero or even negative momentum transfer (Grachev and Fairall, 2001). Therefore the significantly lower A12 results for the tropical ocean (the trade wind region) and months of low winds elsewhere could mean that most momentum transfer calculations are overestimated. This matter needs further study, preferably with new empirical datasets.

\section{Conclusions}

We show that the choice of drag coefficient parameterization can lead to significant differences in resultant momentum flux (or wind stress) values. The differences between the highest and lowest parameterizations are $14 \%$ in the Arctic, the NA, and globally, and they are higher in low winds areas. The parameterizations generally have a decreasing trend in the resultant momentum flux values, with the most recent (Andreas et al., 2012) producing the lowest wind stress values, especially at low winds, resulting in almost $20 \%$ differences in the tropics. The differences can be much larger on monthly scales, up to $29 \%$ in the NA and $36 \%$ in the EA (in months of low winds) and even $50 \%$ locally in the area west of Spitsbergen. For months with the highest winds, the differences are smaller (about $7 \%$ everywhere), but because the flux values are largest with high winds this discrepancy is also important for airsea momentum flux values. Since momentum flux is an important parameter in ocean circulation modeling, we believe more research is needed, and the parameterizations used in the models possibly need upgrading.

\section{Acknowledgements}

We would like to express our gratitude to Ed Andreas for inspiring us. His untimely departure is an irreplaceable loss to the air-sea exchange community. We would also like to thank the entire OceanFlux team. This publication was financed with funds from Leading National Research Centre (KNOW) received by the Centre for Polar Studies for the period 2014-2018 and from OceanFlux Greenhouse Gases Evolution, a project funded by the European Space Agency, ESRIN Contract No. 4000112091/14/I-LG. 


\section{References}

Andreas, E. L., Mahrt, L., and Vickers, D.: A new drag relation for aerodynamically rough flow over the Ocean, J. Atmos. Sci., 69(8), 2520-2539, doi:10.1175/JAS-D-11-0312.1, 2012.

Bigdeli, A., Loose, B., Nquyen, A.T., and Cole, S. T.: Numerical investigation of the Arctic ice-ocean boundary layer and implications for air-sea gas fluxes, Oce. Sci., 13, 61-75, doi:10.5194/os-13-61-2017, 2017.

Brodeau, L., Barnier, B., Gulev, S. K., and Woods, C.: Climatologically significant effects of some approximations in the bulk parameterizations of turbulent air-sea fluxes, J. Phys. Oceanogr., 47(1), 5-28, doi:10.1175/JPO-D-16-0169.1, 2017.

Bunker, A. F.: Computations of surface energy flux and annual air-sea interaction cycles of the North Atlantic Ocean, Mon. Weather Rev., 104(9), 1122-1140, doi:10.1175/15200493(1976)104<1122LCOSEFA>2.0.CO;2, 1976.

Charnock, H.: Wind stress on a water surface, Quart. J. Roy. Meteor. Soc., 81, 639-640, doi:10.1002/qj.49708135027 551.554:551.465, 1955.

Chelton, D. B., and Freilich, M. H.: Scatterometer-Based Assessment of 10-m Wind Analyses from the Operational ECMWF and NCEP Numerical Weather Prediction Models, MWR, Mon. Weather Rev., 133, 409-429, 2005.

Collins, W. D., Bitz, C. M., Blackmon, M. L., Bonan, G. B., Bretherton, S. C., Carton, A. J., Chang, P., Doney, S. C., Hack, J. J., Henderson, T. B., Kiehl, J. T., Large, W. G., McKenna, D. S., Santer, B. D., and Smith, R. D.: The Community Climate System Model version 3 (CCSM3), J. Climate, 19(11), 2122-2143, doi:10.1175/JCLI3761.1, 2006.

Donelan, M. A., Drennan, W. M., and Katsaros, K. B.: The air-sea momentum flux in conditions of wind sea and swell, J. Phys. Oceanogr., 27(10), 2087-2099, doi:10.1175/1520-0485(1997)027<2087:TASMFI>2.0.CO;2, 1997.

Dukhovskoy, D. S., Bourassa, M. A., Peterson, G. N., and Steffen, J.: Comparison of the surface vector winds from atmospheric reanalysis and scatterometer-based wind products over the Nordic Seas and the northern North Atlantic and their application for ocean modeling, J. Geophys. Res.: Oceans, 122, 1943-1973, doi:10.1002/2016JC012453, 2017.

Enriquez, A. G., and Friehe, C. A.: Bulk parameterization of momentum, heat, and moisture fluxes over a coastal upwelling area, J. Geophys. Res.: Oceans, 102(C3), 5781-5798, doi:10.1029/96JC02952, 1997.

Fairall, C. W., Bradley, E. F., Hare, J. E., Grachev, A. A., and Edson, J. B.: Bulk parameterization of air-sea fluxes: updates and verification for the COARE algorithm, J. Climate, 16(4), 571-591, doi:10.1175/1520-0442(2003)016<0571:BPOASF>2.0.CO;2, 2003.

Fer, I.: Weak vertical diffusion allows maintenance of cold halocline in the central Arctic, Atmos. and Oce. Sci. Lett., 2(3), 148-152, 2009.

Foreman, R. J., and Emeis, S.: Revisiting the definition of the drag coefficient in the marine atmospheric boundary layer, J. Phys. Oceanogr., 40, doi:10.1175/2010JPO4420.1, 2010.

Garratt, J. R.: Review of drag coefficients over oceans and continents. Mon. Weather Rev., 105 (7), 915-929, doi:10.1175/1520-0493(1977)105<0915:RODCOO>2.0.CO;2, 1977. 
Geernaert, G. L., Katsoros, K. B., and Richter, K.: Variation of the drag coefficient and its dependence on sea state, J. Geophys. Res., 91(C6), 7667-7679, doi:10.1029/JC091iC06p07667, 1986.

Geernaert, G. L., Larsen, S. E. , and Hansen, F.: Measurements of the wind stress, heat flux, and turbulence intensity during storm conditions over the North Sea, J. Geophys. Res.: Oceans, 92(C13), 13127-13139, doi:10.1029/JC092iC12p13127, 1987.

Geernaert, G. L.: Bulk parameterizations for the wind stress and heat flux. Surface Waves and Fluxes, Vol. I, G. L., Geernaert and W. L., Plant, Eds. Kluwer, 91-172, 1990.

Gerbi, G. P., Trowbridge, J. H., Edson, J. B., Plueddemann, A. J., Terray, E. A., and Fredericks, J. J.: Measurements of momentum and heat transfer across the air-sea interface. J. Phys. Oceanogr., 38(5), 1054-1072. doi:10.1175/2007JPO3739.1, 2008.

Grachev, A. A., and Fairall, C. W.: Upward Momentum Transfer in the Marine Boundary Layer, J. Phys. Oceanogr., 31(7), 1698-1711, doi.org/10.1175/15200485(2001)031<1698:UMTITM>2.0.CO;2, 2001.

Guan, C., and Xie, L.: On the linear parameterization of drag coefficient over sea surface, J. Phys. Oceanogr., 34(12), 2847-2851, https://doi.org/10.1175/JPO2664.1, 2004.

Hanley, K. E., and Belcher, S. E.: Wave-Driven Wind Jets in the Marine Atmospheric Boundary Layer, J. Atmos. Sci., 65(8), 2646-2660, doi.org/10.1175/2007JAS2562.1, 2008.

Jarosz, E., Mitchell, D. A., Wang, D. W., and Teague, W. J.: Bottom-up determination of airsea momentum exchange under a major tropical cyclone, Science, 315, 1707-1709, 2007.

Jones, I. S. F., and Toba, Y.: Wind stress over the ocean. Cambridge University Press, New York, 2001.

Kalnay, E., Kanamitsu, M., Kistler, R., Collins, W., Daeven, D., Gandin, L., Iredell, M., Saha, S., White, G., Woollen, J., Zhu, Y., Chelliah, M., Ebisuzaki, W., Higgins, W., Janowiak, J., Mo, K. C., Ropelewski, C., Wang, J., Leetmaa, A., Reynolds, R., Jenne, R., and Joseph, D.: The NCEP/NCAR 40-year reanalysis project, Bull. Amer. Meteor. Soc., 77(3), 437-471, 1996.

Kukulka, T., Hara, T., and Belcher, S. E.: A model of the air-sea momentum flux and breaking-wave distribution for strongly forced wind waves, J. Phys. Oceanogr., 37(7), 1811-1828, doi:10.1175/JPO3084.1, 2007.

Large, W. G., and Pond, S.: Open ocean momentum flux measurements in moderate to strong winds, J. Phys. Oceanogr., 11(3), 324-336, doi:10.1174/15200485(1981)011<0324:OOMFMI>2.0.CO;2, 1981.

Large, W. G., and Yeager, S. G.: Diurnal to decadal global forcing for ocean and sea-ice models: the data sets and flux climatologies, Technical Note NCAR/TN-460+STR, NCAR, Boulder, CO, 2004.

Lüpkes, C., Gryanik, V. M., Hartmann, J., and Andreas, E. L.: A parameterization, based on sea-ice morphology, of the neutral atmpsheric drag coefficients for weather prediction and climate models, J. Geophys. Res.: Atmospheres, 117(D13), doi:10.1029/2012JD01763, 2012.

Peng, S., and Li, Y.: A parabolic model of drag coefficient for storm surge simulation in the South China Sea, Sci. Rep., 5(15496), doi:10.1038/srep15496, 2015. 
Rieder, K. F., Smith, J. K., and Weller, R. A.: Observed directional characteristics of the wind, wind stress, and surface waves on the open ocean, J. Geophys. Res.: Oceans., 99(C11), 589-596, doi:10.1029/94JC02215, 1994.

Sahlée, E., Drennan, W. M., Potter, H. , and Rebozo, M. A.: Waves and air-sea fluxes from a drifting asis buoy during the southern ocean gas exchange experiment, J. Geophys. Res.: Oceans, 117(C08003), doi: 10.1029/2012JC008032, 2012.

Shutler, J. D., Piolle, J-F., Land, P. E., Woolf, D. K., Goddijn-Murphy, L., Paul, F., GirardArdhuin, F., Chapron, B., and Donlon, C. J.: FluxEngine: a flexible processing system for calculating air-sea carbon dioxide gas fluxes and climatologies, J. Atmos. Oceanic Technol., 33(4), 741-756, doi:10.1175/JTECH-D-14-00204.1, 2016.

Taylor, G. I.: Skin friction of the wind on the Earth's surface, Proc. Roy. Soc. London, A92, 196-199, 1916.

Trenberth, K. E., Large, W. G., and Olson, J. G.: The effective drag coefficient for evaluating wind stress over the Oceans, J. Climate, 2(12), 1507-1516, doi:10.1175/15200422(1989)002<1507:TEDCFE>2.0.CO;2, 1989.

$\mathrm{Wu}, \mathrm{J} .:$ Wind stress and surface roughness at air-sea interface, J. Geophys. Res., 74(2), 444455, doi:10.1029/JB074i002p00444, 1969.

$\mathrm{Wu}$, J.: Wind stress coefficients over the sea surface near neutral conditions - A revisit, J. Phys. Oceanogr., $\quad$ 10(5), 727-740, doi:10.1175/15200485(1980)010<0727:WSCOSS >2.0.CO;2, 1980.

$\mathrm{Wu}$, J.: Wind-stress coefficients over sea surface from breeze to hurricane, J. Geophys. Res., 87(C12), 9704-9706, doi: 10.1029/JC087iC12p09704, 1982.

Zilitinkiewicz, S. S., Monin, A. S., and Czalikow, S. W.: Dynamika Morza. Wzajemne oddziaływanie morza i atmosfery, Studia i materiały oceanologiczne, vol. 22. Poland, 1978.

Yelland, M., and Taylor, P. K.: Wind stress measurements from the open ocean, J. Phys. Oceanogr., 26(4), 541-558, doi:10.1175/1520-0485(1996)026<0541:WSMFTO>2.0.CO;2, 1966. 
Table 1. Average annual mean values of momentum flux (wind stress) $\left[\mathrm{N} \mathrm{m}^{-2}\right]$ for all the studied regions and parameterizations. In each column the percentage values are normalized to A12, the parameterization that produced the smallest average flux values.

Figure 1. The drag coefficient parameterization used in the study (Eqs. 8-14) as a function of wind speed $\mathrm{U}_{10}\left(\mathrm{~m} \mathrm{~s}^{-1}\right)$.

Figure 2. Maps of momentum flux $\left[\mathrm{N} \mathrm{m}^{-2}\right]$ across the sea surface (wind stress) for boreal winters ((a) and (c)) and summers ((b) and (d)) for Wu (1969) and A12 drag coefficient parameterizations (the two parameterizations with the highest and lowest average values, respectively).

Figure 3. Monthly average momentum flux values $\left[\mathrm{N} \mathrm{m}^{-2}\right]$ for (a) global ocean, (b) North Atlantic, (c) European Arctic, and (d) tropical ocean. The regions are defined in the text.

Figure 4. The drag coefficient values for Large and Yeager (2004) and Andreas et al., (2012) parameterization as a function of wind speed $\mathrm{U}_{10}\left(\mathrm{~m} \mathrm{~s}^{-1}\right)$.

Figure 5. Annual average momentum flux values for (a) European Arctic and (b) Tropical ocean. The vertical solid line is the average of all seven parameterization and the dashed lines are standard deviations for the presented values. Global and the North Atlantic results are not shown because the relative values for different parameterizations are very similar (see Table 1), scaling almost identically between the basins.

Figure 6. Annual mean wind speed $\mathrm{U}_{10}\left(\mathrm{~m} \mathrm{~s}^{-1}\right)$ in the study area-the North Atlantic and the European Arctic (north of the red line). 
Ocean Sci. Discuss., https://doi.org/10.5194/os-2018-61

Manuscript under review for journal Ocean Sci.

Discussion started: 26 June 2018

(c) Author(s) 2018. CC BY 4.0 License.

Table 1. Average annual mean values of momentum flux (wind stress) $\left[\mathrm{N} \mathrm{m}^{-2}\right]$ for all the studied regions and parameterizations. In each column the percentage values are normalized

501 to $\mathrm{A} 12$, the parameterization that produced the smallest average flux values.

502

\begin{tabular}{|l|c|c|c|c|c|}
\hline & Global & North Atlantic & Arctic & W. Spitsbergen & Tropics \\
\hline Wu (1969) & $\begin{array}{c}0.322 \\
(114 \%)\end{array}$ & $\begin{array}{c}0.330 \\
(114 \%)\end{array}$ & $\begin{array}{c}0.375 \\
(114 \%)\end{array}$ & $\begin{array}{c}0.360 \\
(114 \%)\end{array}$ & $\begin{array}{c}0.261 \\
(119 \%)\end{array}$ \\
\hline Garratt (1977) & $\begin{array}{c}0.307 \\
(109 \%)\end{array}$ & $\begin{array}{c}0.316 \\
(109 \%)\end{array}$ & $\begin{array}{c}0.358 \\
(109 \%)\end{array}$ & $\begin{array}{c}0.344 \\
(110 \%)\end{array}$ & $\begin{array}{c}0.251 \\
(115 \%)\end{array}$ \\
\hline Wu (1982) & 0.311 & 0.320 & 0.363 & 0.349 & 0.255 \\
& $(110 \%)$ & $(110 \%)$ & $(110 \%)$ & $(111 \%)$ & $(117 \%)$ \\
\hline NCEP/NCAR & 0.303 & 0.312 & 0.353 & 0.341 & 0.258 \\
& $(107 \%)$ & $(107 \%)$ & $(107 \%)$ & $(108 \%)$ & $(118 \%)$ \\
\hline Yelland \& & 0.297 & 0.306 & 0.348 & 0.335 & 0.245 \\
Taylor (1996) & $(105 \%)$ & $(105 \%)$ & $(106 \%)$ & $(107 \%)$ & $(112 \%)$ \\
\hline Large \& & 0.285 & 0.293 & 0.333 & 0.320 & 0.236 \\
Yeager (2004) & $(101 \%)$ & $(101 \%)$ & $(101 \%)$ & $(102 \%)$ & $(108 \%)$ \\
\hline $\begin{array}{l}\text { Andreas et al., } \\
\text { (2012) }\end{array}$ & 0.283 & 0.290 & 0.329 & 0.314 & 0.219 \\
\hline
\end{tabular}

510

511

512

513

514

515

516 
Ocean Sci. Discuss., https://doi.org/10.5194/os-2018-61

Manuscript under review for journal Ocean Sci.

Discussion started: 26 June 2018

(c) Author(s) 2018. CC BY 4.0 License.

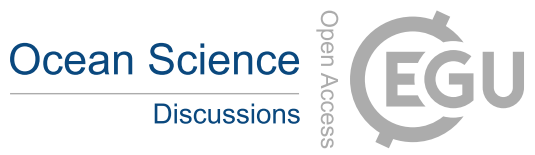

517 Figure 1. The drag coefficient parameterization used in the study (Eqs. 8-14) as a function of 518 wind speed $\mathrm{U}_{10}\left(\mathrm{~m} \mathrm{~s}^{-1}\right)$.

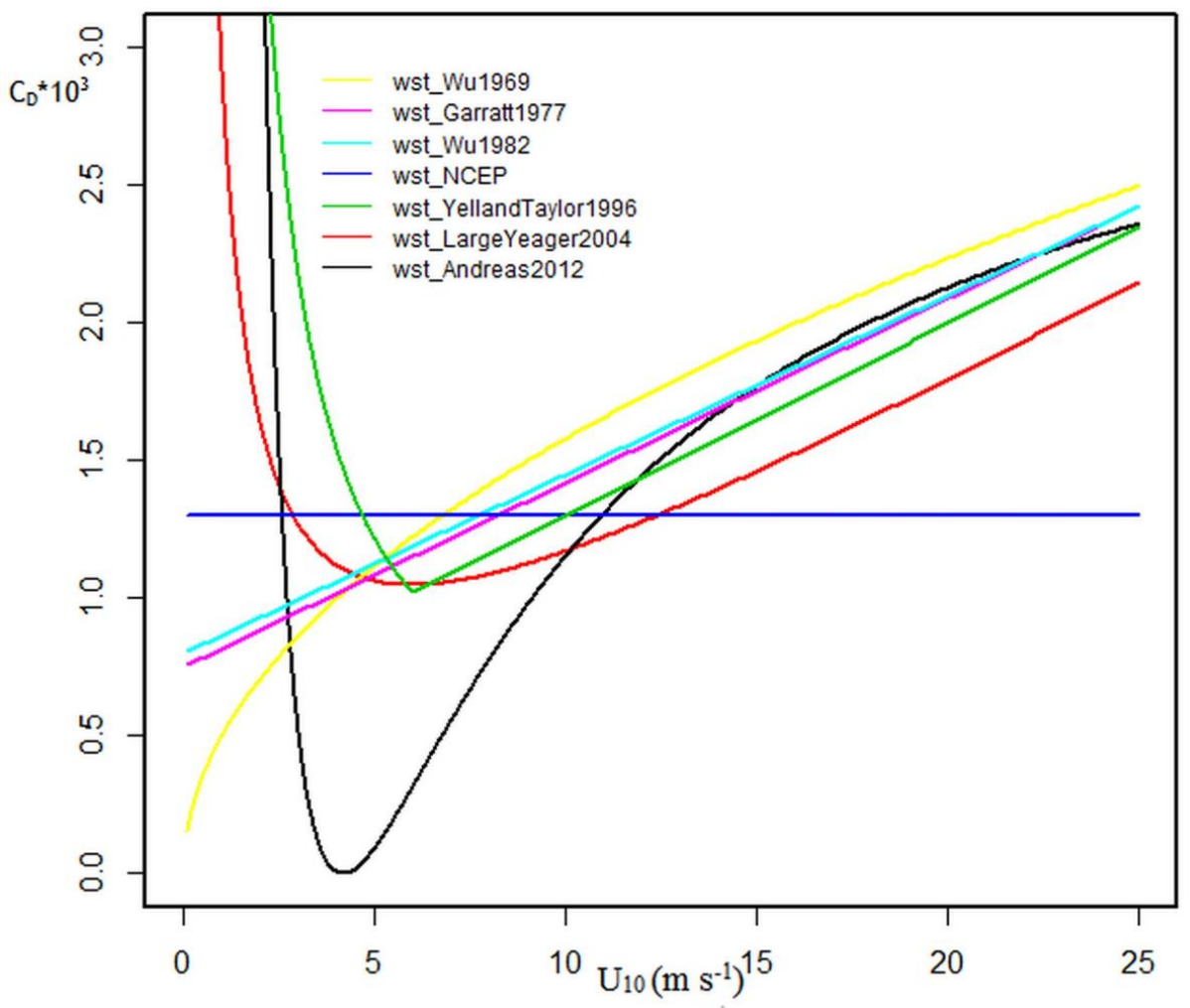


Ocean Sci. Discuss., https://doi.org/10.5194/os-2018-61

Manuscript under review for journal Ocean Sci.

Discussion started: 26 June 2018

(c) Author(s) 2018. CC BY 4.0 License.

529

530

531

532

533

534

(a) Wu, (1969)

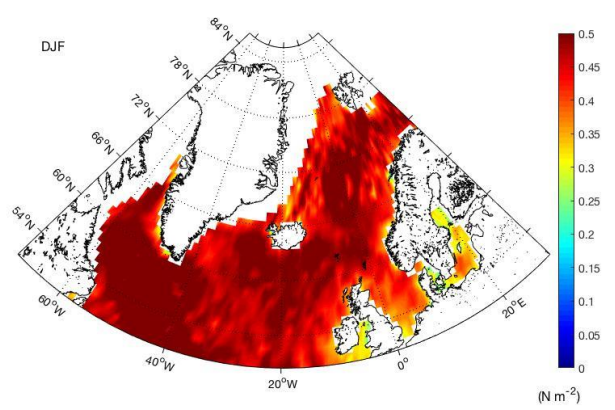

536

(c) Andreas, et al., (2012)

537

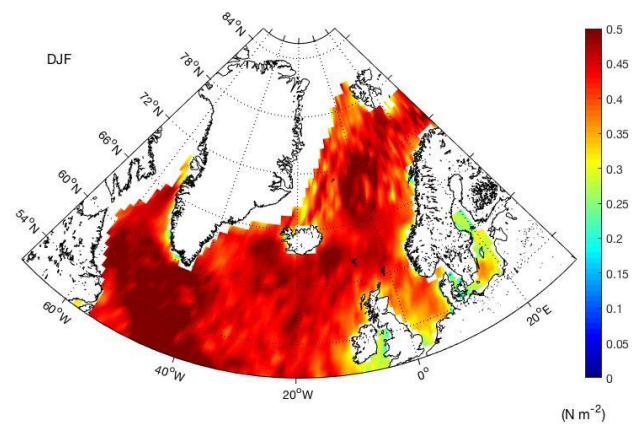


Ocean Sci. Discuss., https://doi.org/10.5194/os-2018-61

Manuscript under review for journal Ocean Sci.

Discussion started: 26 June 2018

(c) Author(s) 2018. CC BY 4.0 License.

545 Figure 3. Monthly average momentum flux values $\left[\mathrm{N} \mathrm{m}^{-2}\right]$ for (a) global ocean, (b) North 546 Atlantic, (c) European Arctic, and (d) Tropical ocean. The regions are defined in the text.

547 (a)

\section{Global ocean mean momentum flux}

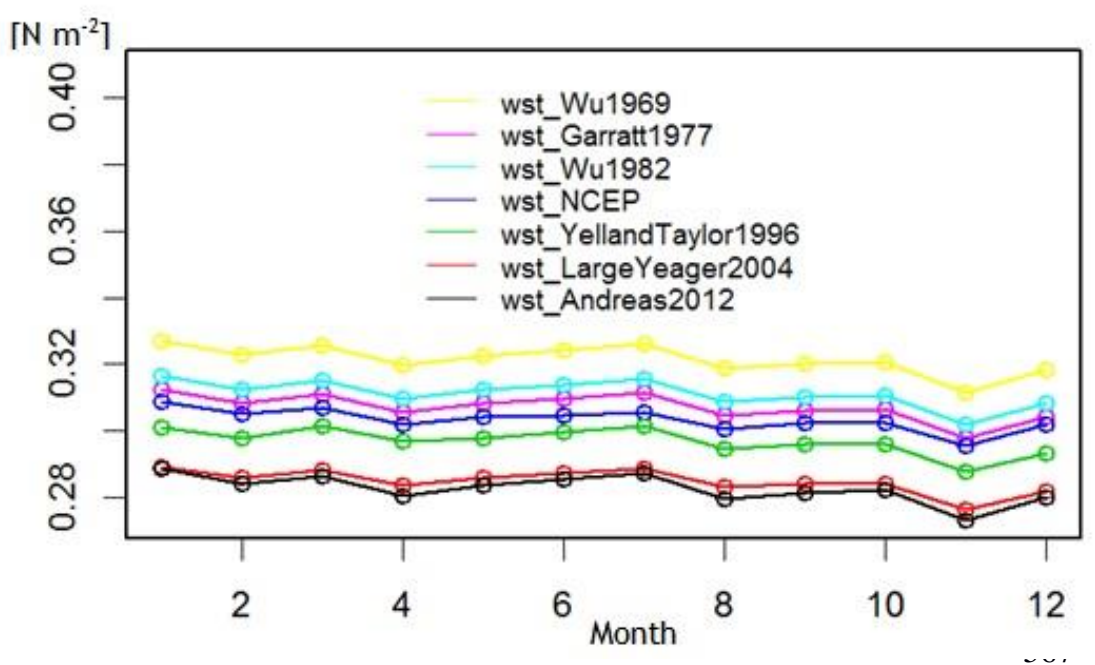

(b)

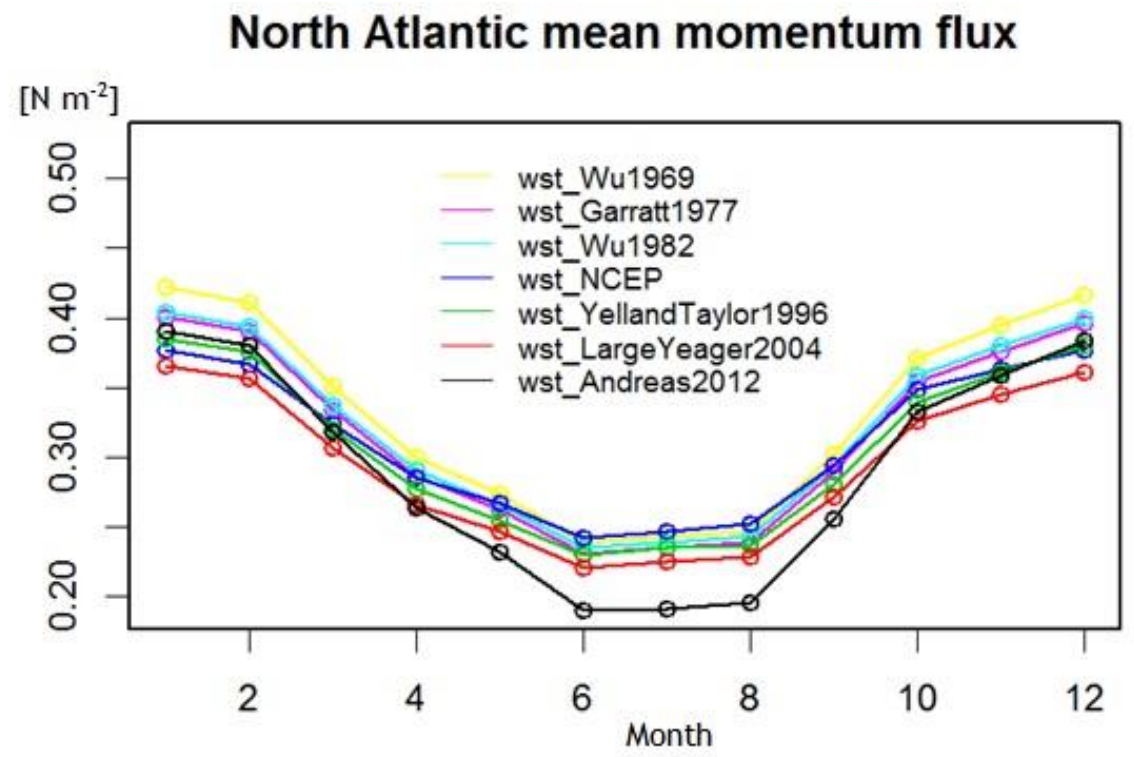


Ocean Sci. Discuss., https://doi.org/10.5194/os-2018-61

Manuscript under review for journal Ocean Sci.

Discussion started: 26 June 2018

(c) Author(s) 2018. CC BY 4.0 License.

(d)

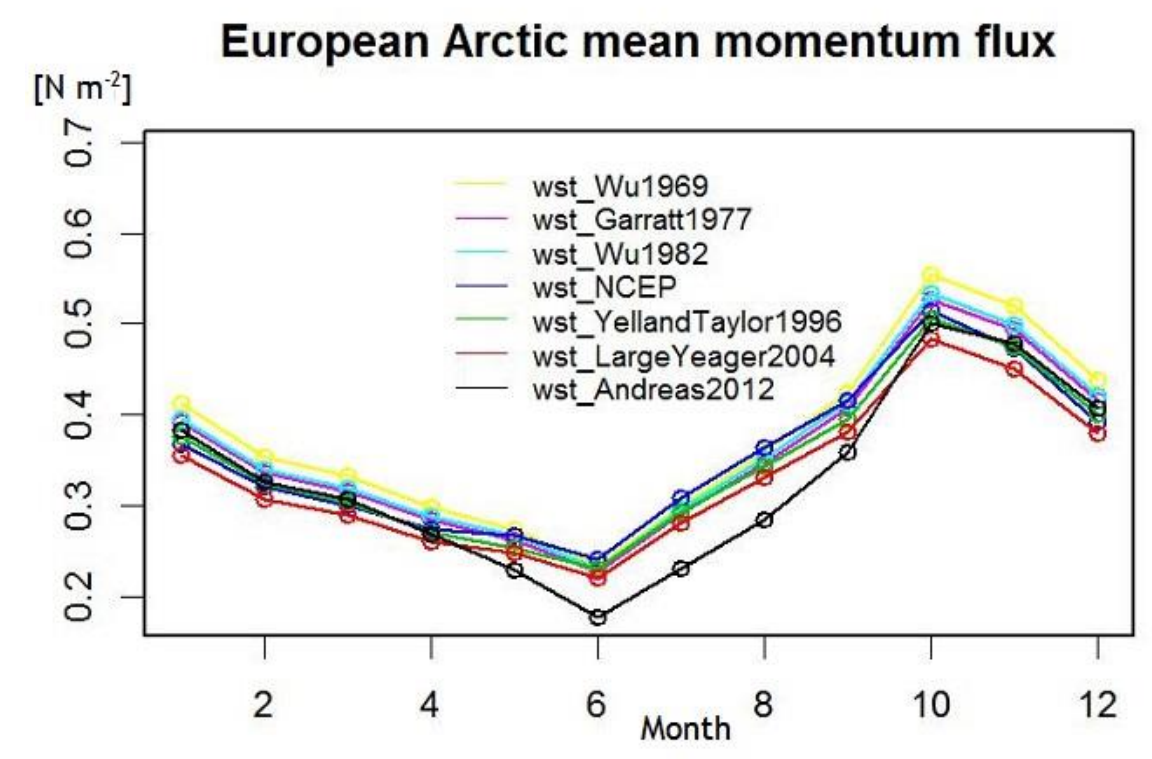

586

Tropical Ocean mean momentum flux

588

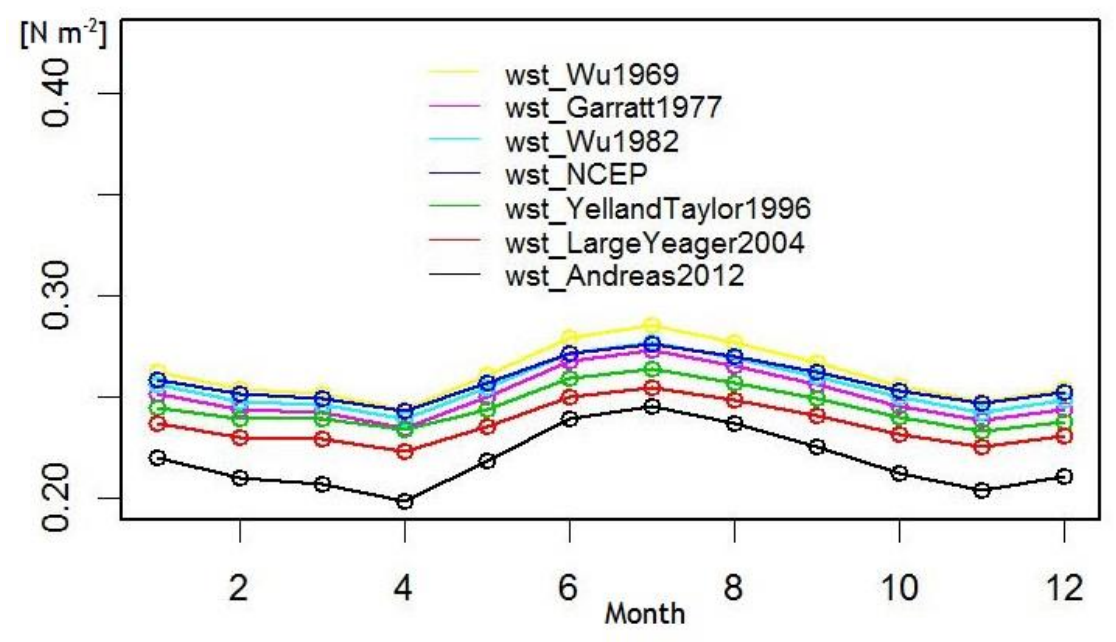


Ocean Sci. Discuss., https://doi.org/10.5194/os-2018-61

Manuscript under review for journal Ocean Sci.

Discussion started: 26 June 2018

(c) Author(s) 2018. CC BY 4.0 License.

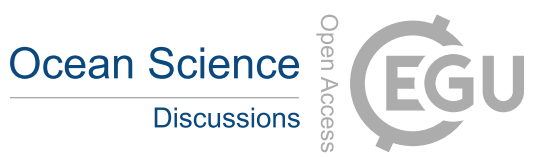

(c) (i)

599 Figure 4. The drag coefficient values for Large and Yeager (2004) and Andreas et al., (2012)

600 parameterization as a function of wind speed $\mathrm{U}_{10}\left(\mathrm{~m} \mathrm{~s}^{-1}\right)$.

601

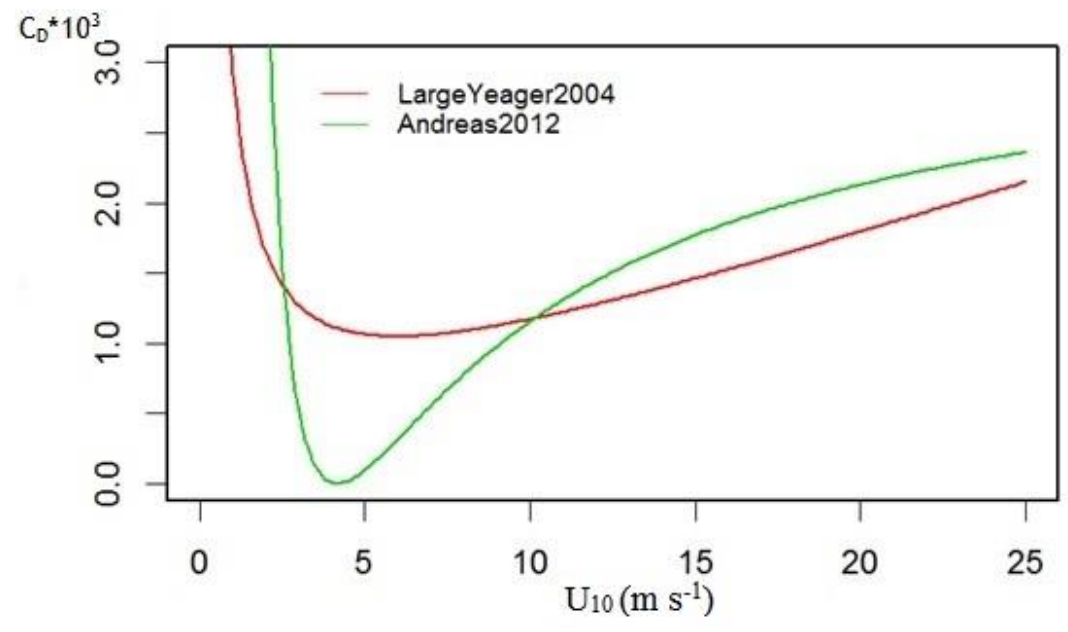

602

603

604

605

606

607

608

609

610

611

612

613

614

615

616

617

618

619

620

621

622

623

624

625

626 
Ocean Sci. Discuss., https://doi.org/10.5194/os-2018-61

Manuscript under review for journal Ocean Sci.

Discussion started: 26 June 2018

627 Figure 5. Annual average momentum flux values for (a) European Arctic and (b) Tropical 628 ocean. The vertical solid line is the average of all seven parameterization and the dashed lines 629 are standard deviations for the presented values. Global and the North Atlantic results are not 630 shown because the relative values for different parameterizations are very similar (see Table 631 1), scaling almost identically between the basins.

$632 \quad(\mathbf{a})$

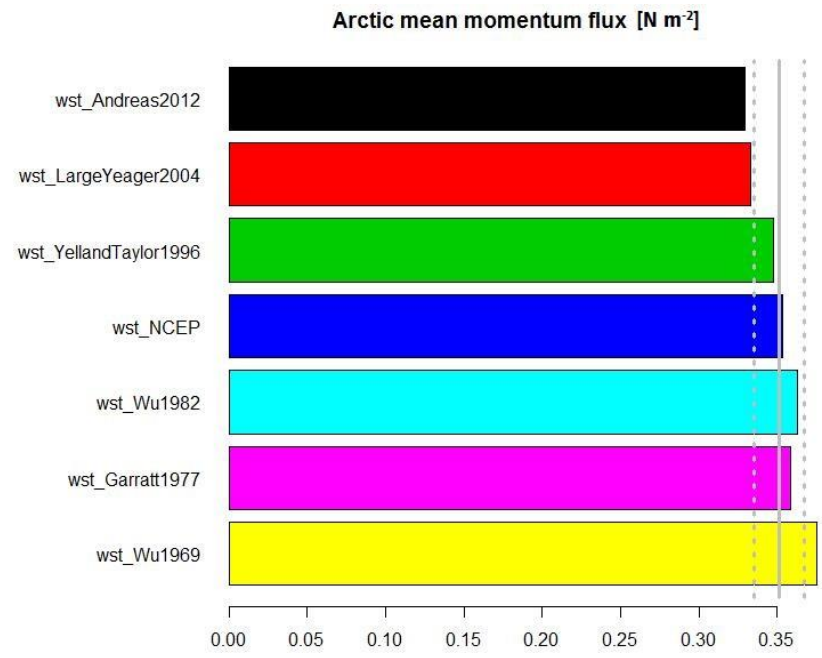

641

(b)

)

642

643

644

645

646

wst_Andreas2012

wst_LargeYeager2004

wst_YellandTaylor1996

wst_NCEP

wst_Wu1982

wst_Garratt1977

wst_Wu1969

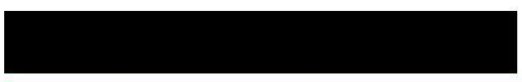

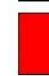
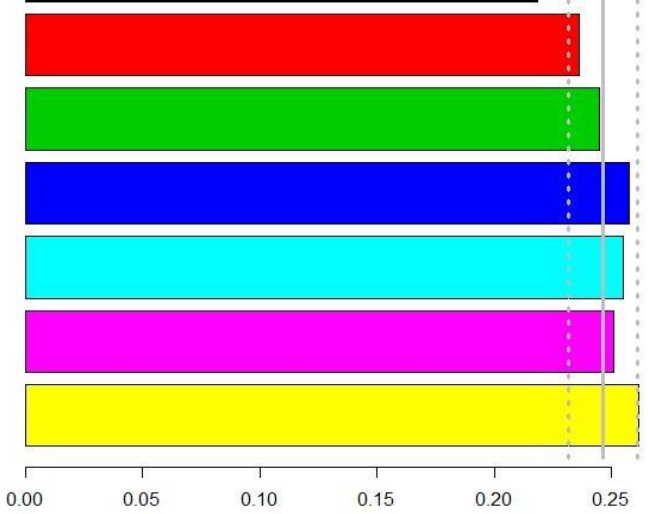
Ocean Sci. Discuss., https://doi.org/10.5194/os-2018-61

Manuscript under review for journal Ocean Sci.

Discussion started: 26 June 2018

(c) Author(s) 2018. CC BY 4.0 License.

655 Figure 6. Annual mean wind speed $\mathrm{U}_{10}\left(\mathrm{~m} \mathrm{~s}^{-1}\right)$ in the study area- the North Atlantic and the 656 European Arctic (north of the red line).

657

658

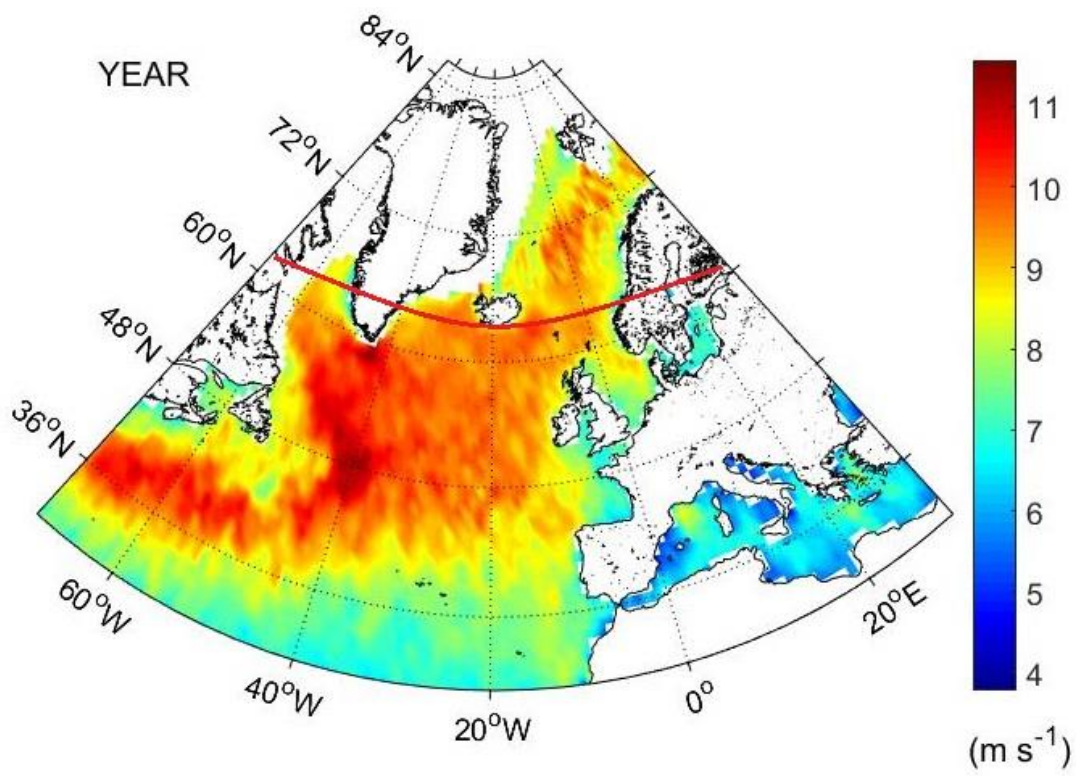

